\section{PENENTUAN NILAI FIELD CAPACITY PADA SAMPAH SEGAR DAN SAMPAH LAMA}

\section{$\operatorname{Samin}^{1}$}

Staf Pengajar Jurusan Teknik Sipil

Fakultas Teknik - Univ. Muhammadiyah Malan$$
\text { e-mail: }
$$

\section{ABSTRACT}

In determining leachate generation, the value of field capacity waste is one of the parameters that determine the amount of leachate which is formed against, because the field capacity (FC) is water entering the landfill waste then the water will come out into leachate. In this study we have performed research on the determination of field capacity on fresh waste and old waste. The result of this research showed that the value of FC is inflenced by age waste. The value of field capacity (FC) on fresh wate is greater hat old waste a value of field capacity $(\mathrm{FC})$ is smaller.

Keywords: leachate, field capacity, waste

\section{PENDAHULUAN}

Berbagai masalah yang ditimbulkan akibat kuantitas maupun kualitas leachate menjadi salah satu isu utama dalam pencemaran lingkungan yang menyebabkan keberadaan landfill tidak diinginkan oleh sebagian masyarakat. Penanganan leachate yang ada di TPA, harus dimulai dengan penentuan beban (karakteristik) dan produksi leachate. Konsep keseimbangan air digunakan dan dikembangkan para peneliti di beberapa negara, untuk menentukan timbulan leachate di suatu landfill, seperti Thornthwite dan HELP Model.

Beberapa hal yang dipertimbangkan dalam penentuan timbulan lindi menggunakan konsep keseimbangan air, baik Thornthwaite maupun HELP model adalah kondisi iklim dan kondisi landfil serta karakteristik sampah. Kondisi iklim di sekitar landfill seperti curah hujan, temperatur, kelembaban, lama penyinaran matahari dan kelenbaban, lama penyina dan tinggi dan luas landfill, type landfill dan pola operasional harian landfill. Sedangkan karakteristik sampah yang harus diperhatikan antara lain densitas sampah, komposisi sampah dan field capacity sampah.

Dalam penentuan timbulan lindi, nilai field capacity sampah salah satu parameter yang menentukan terhadap banyaknya lindi yang erbentuk, karena field capacity merupakan jumlah air yang mungkin disimpan oleh sampah hingga sampah mengalami jenuh air dan akhirnya apabila masih ada air yang masuk dalam timbunan sampah maka air akan keluar menjadi lindi.

Kemampuan landfill untuk menyimpan air kan mempengaruhi banyaknya timbulan leachate yang salah satunya tergantung oleh besarnya nilia field capacily sampah, Field capacity sampah merupakan jumlah air yang tersimpan dalam sampah akibat gaya kohesi dan adhesi atau kada air, yang mana air secara gravitasi akan mengali ke bawah, sehingga hanya air kapiler ai higroskopik yang tinggal atau menempel pada suatu partikel (Notodarmojo, 2005).

Semakin tinggi nilai field capacity sampah maka jumlah timbulan leachate menjadi kecil da sebaliknya apabila nilai field capacity sampah kecil, timbulan leachate semakin besar. Penelitian tentang field capacity yang dilakukan oleh Jang dkk., 2001), menyimpukan bahwa propertis hicrolik termasuk field capacity sampa mempengaruhi produksi leachate. Sementara itu,
Kampus III, Jl. Tlogomas No. 246 Telp. (0341) 464318-319 Pes. 130 Fax. (0341) 460435 amount of water that may be stored by the waste until it has saturated the water and ultimately if the
Warith dkk., (2005) menyebutkan bahwa nilai field capacity sampah dipengaruhi oleh komposisi sampah, kepadatan sampah, porositas, ukuran partikel, tanah sampah, dan umur sampah.

Biodegradasi sampah dalam suatu landfil akan berlangsung dalam kurun waktu yang panjang dan dipengaruhi oleh jumlah air, $\mathrm{pH}$, temperature derajat kepadatan, umur, dan komposisi sampah (Qasim dan Chiang, 1994). Komposisi sampah di Indonesia yang kandungan organiknya relative besar yaitu sekitar $60 \%$ (Damanhuri dkk., 2010), tentunya akan mempengaruhi proses biodegradasi sampah. Karakteristik sampah yang telah mengalami proses biodegradasi, terutama sifa fisiknya seperti kadar air, berat jenis, kandungan volatile dan nilai field capacity sampah, sert koefisien permeabilitas sampah, akan mengalami perubahan.

Namun demikian belum tersedianya dat timbulan lindi dan nilai field capacity sampah Indonesia, mengakibatkan penentuan timbulan leachate selama ini masih menggunakan data field capacity sampah dari negara lain dan belum tentu cocok dengan karakteristik sampah di Indonesia Penelitian tentang nilai field capacity sampah diharapkan akan dapat menjawab hambata tersebut.

Kapasitas Penyimpanan Sampah

Sampah dan tanah penutup karena sifat-sifat dan proses yang terjadi, air dapat tertahan atau tersimpan dengan jumlah sesuai dengan kemampuan materialnya atau moisture storage. Setelah kapasitas tampungan terlampaui dan akibat

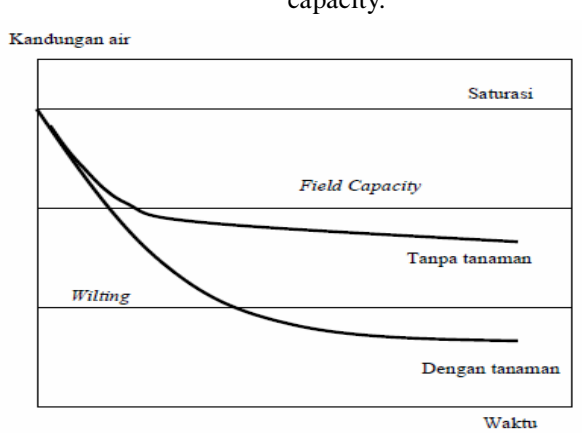

Gambar 1. Konsep kandungan air dalam tanah 2008) capacity. 2008). capacity. gaya gravitasi maka air tersebut akan mengalir dan

Kapasitas penyimpanan air suatu landfill dicirikan oleh besarnya nilai wilting point dan field capacity materi yang ada di dalam landfill. Gambar 1 , menjelaskan konsep kandungan air dalam tanah, dimana ketika curah hujan terjadi di suatu tempat dengan intensitas dan durasi tertentu, tanah akan mengalami jenuh air Selanjutnya, akibat adanya gaya gravitasi dan gaya kohesi air akan bergerak kebawah sehingga kandungan air dalam tanah akan berkurang hingga nilai tertentu yang disebut field

Kapasitas Penyimpanan Sampah

Sampah dan tanah penutup karena sifat-sifat dan proses yang terjadi, air dapat tertahan atau tersimpan dengan jumlah sesuai dengan kemampuan materialnya atau moisture storage. Setelah kapasitas tampungan terlampaui dan akibat gaya gravitasi maka air tersebut akan mengalir dan keluar dari landfill menjadi leachate (Damanhuri,

Kapasitas penyimpanan air suatu landfill dicirikan oleh besarnya nilai wilting point dan field capacity materi yang ada di dalam landfill. Gambar 1, menjelaskan konsep kandungan air dalam tanah, dimana ketika curah hujan terjadi di suatu tempat dengan intensitas dan durasi tertentu, tanah akan mengalami jenuh air. Selanjutnya, akibat adanya gaya gravitasi dan gaya kohesi air akan bergerak kebawah sehingga kandungan air dalam tanah akan berkurang hingga nilai tertentu yang disebut field

70 |Media Teknik Sipil, Volume 9, Nomor 1, Februari 2011: 70 - 
Menurut Bendz dkk., (1997), dalam tulisannya masuk dalam landfill hampir tidak ada. Selanjutnya yang berjudul "accumulatif of water and generation jumlah air yang tersimpan dalam landfill dibagi of leachate in young landfill" mengulas tentang dengan kedalaman landfill, mendapatkan nilai , Swedia Jumlah air yang $\mathrm{mm} / \mathrm{m}$. Selanjutnya hubungan antara jumlah air tersimpan water storage atau field capacity dalam yang tersimpan dalam landfill (S) dan jumlah landfill tergantung pada musim, dimana pada bulan leachate (Q), tampak pada Gambar 2, yang Oktober sampai April akumulasi air meningkat dijelaskan dengan persamaaan polinomial deraja sementara pada bulan Mei hingga September dua $\mathrm{Sw}=\mathrm{a}+\hat{\mathrm{a}}_{1} \mathrm{Q}+\hat{\mathrm{a}}_{2} \mathrm{Q}^{2}$ atau menggunakan fungs akumulasi air menurun karena jumlah air yang power $\mathrm{S}=\boldsymbol{a} \boldsymbol{Q}^{b}$

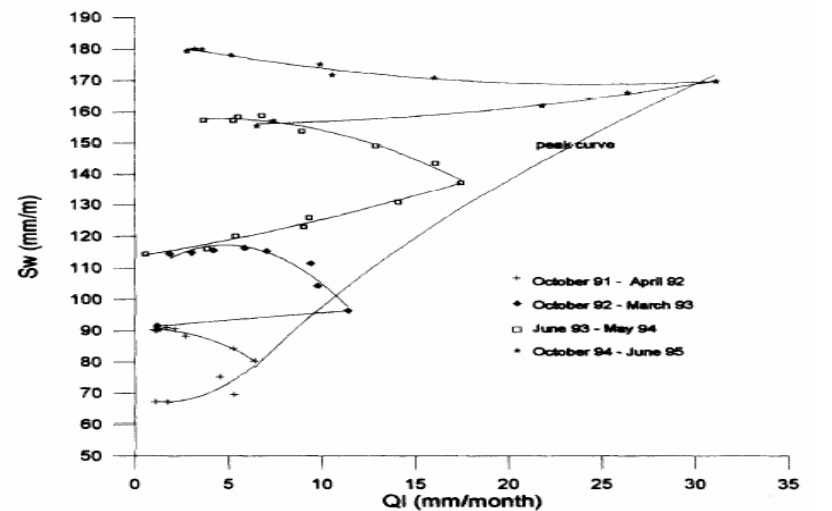

Gambar 2. Hubungan antara Produksi leachate dan penyimpanan air

$$
\text { Sumber : Bendz dkk., (1997) }
$$

Penelitian kemampuan landfill menyimpan field capacity sampah adalah perbandingan bera sejumlah air atau moisture retention ketika ada air yang masuk dalam landfill, dilakukan oleh Dollar, (2005) melalui eksperimen laboratorium dan experimental lapangan dengan membuat landfill ukuran kecil. Hasil penelitian tersebut menunjukkan adanya perubahan moiture retention akibat penambahan ash dan sludge pada eksperimen dimana nilai final moisture contentnya berkisar $89 \%$ yang berarti ada peningkatan jika dibandingkan pada kondisi awal yaitu sebesar $39 \%$.

\section{Field Capacity Sampah}

Field capacity sampah merupakan jumlah air yang tersimpan dalam sampah akibat gaya kohesi dan adhesi atau kadar air yang dimana air gravitasi telah mengalir ke bawah, sehingga hanya air kapiler air higroskopik yang tinggal atau menempel pada suatu partikel (Notodarmojo, 2005). Dalam definisi yang lain menurut Schroeder dkk., (1994) bahwa Gambar3., 72 |Media Teknik Sipil, Volume 9, Nomor 1, Februari 2011: 70 -

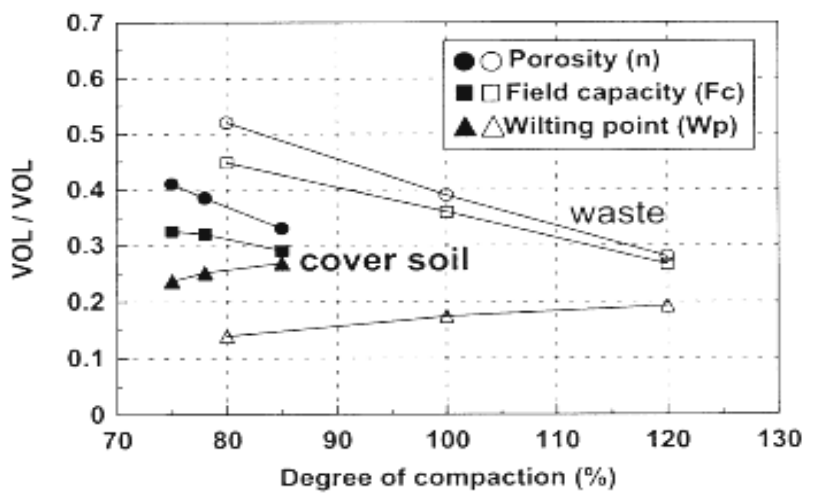

Gambar 3. Pengaruh derajat kepadatan terhadap field capacity Sumber: Jang et.al., (2001)

Selanjutnya Jang dkk., (2001) menjelaskan densitas $600 \mathrm{~kg} / \mathrm{m} 3$, nilai field capacity sampah engaruh densitas sampah terhadap kandungan air adalah sekitar 53\%, sementara pada sampah dengan dalam sampah (Gambar 4). Sampah dengan densitas $1200 \mathrm{~kg} / \mathrm{m} 3$ diperoleh nilai field capacity

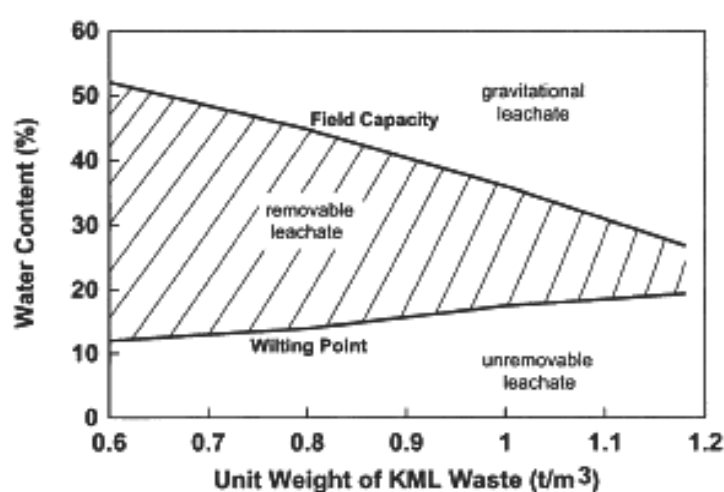

Gambar 4. Hubungan densitas dan field capacity sampah Sumber: Jang et.al., (2001)
Metode penentuan nilai FC menurut Teresa Ortha dkk., (2003), dengan penerapan tambahan beban adalah untuk mensimulasikan efek dar lapisan atasnya atau penimbunan sampah secara berlapis di tempat pembuangan sampah. Hasilnya menunjukkan bahwa semakin tinggi pemadatan lapisan di atasnya, semakin kecil jumlah air yang terserap dalam sampah (FC), dengan demikian jumlah lindi akan meningkat.

Samin ${ }^{I}$. Penentuan nilai field capacity pada sampah segar Dan sampah lama
Disamping itu, di beberapa leteratur menunjukkan bahwa nilai field capacity dipengaruhi oleh densitas sampah, nilai FC bervariasi antara $14 \%$ hingga $44 \%$, seperti yang dikutip oleh Warith dkk., (2005) bahwa sampah dengan densitas $688 \mathrm{~kg} / \mathrm{m} 3$ nilai field capacity berkisar 20 sampai 35\%. Selanjutnya HernándezBerriel dkk., (2008) menjelaskan bahwa Field capacity (FC) dipengaruhi oleh kondisi kelembaban

\begin{abstract}
mpahnya, semakin tinggi derajat kepadatan maka ilai field capacity dan koefisien permeabilitas mpah semakin kecil seperti tampak pada

(1994) bahwa nilai field capacity sampah adalah
sebesar $29 \%$ untuk sampah dengan densitas sebesa

$312 \mathrm{~kg} / \mathrm{m} 3$. Sedangkan Jang dkk, (2001)

sampah dalam kondisi kering atau basah dan berdasarkan ketebalan air yang ada pada ketinggian tertentu $(\mathrm{mm} / \mathrm{m})$ atau field capacity juga hisapan kapiler 0.33 bar. Nilai field capacity dipengaruhi oleh kepadatan, komposisi sampah, ukuran partikel, umur sampah serta efek berat sampah lapisan
\end{abstract} a 
suatu landfill. Semakin tinggi kelembaban, field diperoleh nilai FC sebesar 55,37\%. Beberapa nilai capacity yang diperoleh juga semakin tinggi, pada $\quad$ FC sampah yang telah diperoleh berdasarkan hasi landfill dengan kelembaban 70\% diperoleh FC penelitian terdahulu, disajikan pada Tabel 1, tampa

Tabel 1. Nilai Field capacity sampah

\begin{tabular}{lll}
\hline No & Field Capacity sampah (\%) & Peneliti \\
\hline 1 & 29 & Remson dkk. (1968) \\
2 & $29-42$ & Holmes (1980) \\
3 & $30-40$ & Straub \& Lynch (1982) \\
4 & $20-30$ & Korfiatis dkk.(1990) \\
5 & $20-30$ & Owesis dkk. (1990) \\
6 & 14 & Zeiss and Major (1994) \\
7 & 29 & Schroeder at al. (1994) \\
8 & 44 & Bengtsson dkk. (1994) \\
\hline
\end{tabular}

Sumber :Yuen dkk., (2001)

\section{Biodegradasi Sampah}

Biodegradasi sampah dalam suatu landfill akan berlangsung dalam kurun waktu yang panjang

Sampah yang terdapat dalam landfill, karena dan dipengaruhi oleh jumlah air, $\mathrm{pH}$, temperature, sifat dan faktor lingkungannya akan mengalami derajat kepadatan, umur, dan komposisi sampah suatu proses degradasi. Secara umum degradasi (Qasim dan Chiang, 1994). Komposisi sampah d sampah akan berlangsung dalam waktu yang lama, Indonesia, berdasarkan data Statistik Persampahan dengan mengandalkan keberadaan mikroorganisme $\quad$ Indonesia seperti ditunjukkan pada Tabel 2.

yang ada dalam sampah untuk melakukan

perombakan materi sampah, sehingga proses ini

disebut biodegradasi sampah.

Tabel 2 . Komposisi Sampah di Indonesia

\begin{tabular}{lcc}
\hline Jenis Sampah & $\begin{array}{c}\text { Jumlah } \\
\text { (jutaton/tahun) }\end{array}$ & Persentase (\%) \\
\hline Sampah Dapur & 22,4 & $58 \%$ \\
Sampah Plastik & 5,4 & $14 \%$ \\
Sampah Kertas & 3,6 & $9 \%$ \\
Sampah Lainnya & 2,3 & $6 \%$ \\
Sampah Kayu & 1,4 & $4 \%$ \\
Sampah Kaca & 0,7 & $2 \%$ \\
Sampah Karet/Kulit & 0,7 & $2 \%$ \\
Sampah Kain & 0,7 & $2 \%$ \\
Sampah Metal & 0,7 & $2 \%$ \\
Sampah Pasir & 0,5 & $1 \%$ \\
\hline TOTAL & 38,5 & $100 \%$ \\
\hline
\end{tabular}

Sumber : Statistik Persampahan Indonesia 2008

Berdasarkan tabel di atas, tampak bahwa sampah di negara berkembang seperti Indonesia persentase sampah dapur adalah 58\%, ini adalah tentunya berbeda dengan komposisi sampah di sampah yang memiliki materi organik. Komposisi negara maju, dimana komposisi sampah di
Indonesia dominan berupa sampah organik sedangkan di negara maju berupa sampah kertas.

Menurut Blight dkk, (2000), sampah dengan kandungan material organik lebih dari $20 \%$, maka dikelompokkan sebagai high biodegradable waste. Sedangkan apabila kandungan materi organikny kurang atau sama dengan $20 \%$, maka disebut sebagai low biodegradable waste.

Biodegradasi sampah akan mengakibatkan Banya perubahan karakteristik sampah, seperti properti hidrolik sampah. Hossain dk menjelaskan bahwa ada perubahan propert idrolik sampah selama sampah mengalami proses dekomposisi. Pada sampah segar dengan densitas $700 \mathrm{~kg} / \mathrm{m} 3$, nilai koefisien permeabilitas sampah $0.0088 \mathrm{~cm} /$ det dan setelah sampah mengalan

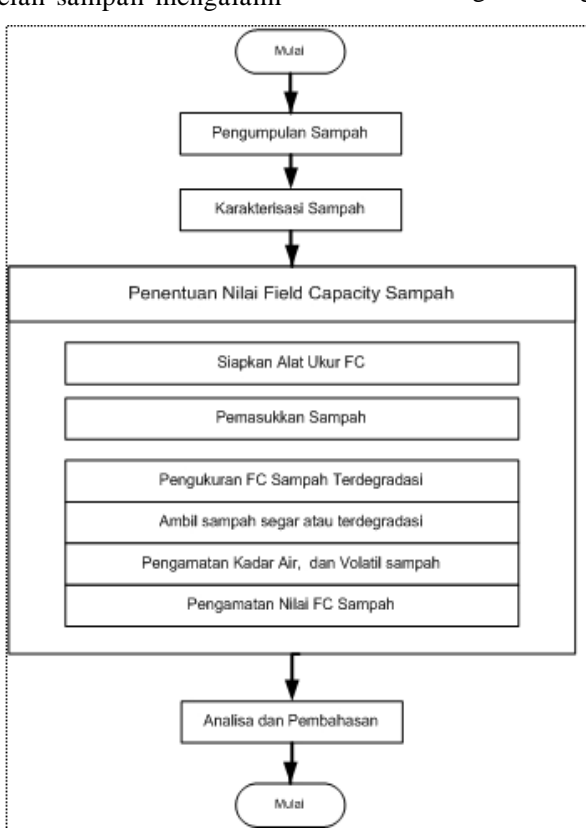

Gambar 5. Alur Penelitia

Sampah segar yang telah dikumpulkan, c. Tentukan kadar air sampah sebelum ditest kemudian diukur nilai field capacity sampah d. Masukkan sampah kedalam alat ukur sesuai sampah, dengan prosedur sebagai berikut :

d. Masukkan sampah kedalam alat ukur sesuai

a. Siapkan alat ukur field capacity sampah e. Atur alat ukur periksa kran dan pastikan (Gambar 6)

b. Timbang alat uku 
f. Tambahkan air bersih secara perlahan, hingga sampah terendam air atau permukaan air berada di atas permukaan sampah.

Keluar air melalui kran outlet, tampung air yang keluar selama 30 menit dan ukur volume air yang keluar.

g. Catat jumlah air yang dimasukkan j. Timbang alat+sampah setelah air dikeluarkan

h. Diamkan selama 24 jam. supava air masuk k. Periksa kadar air sampah setelah ditest kedalam pori-pori sampe

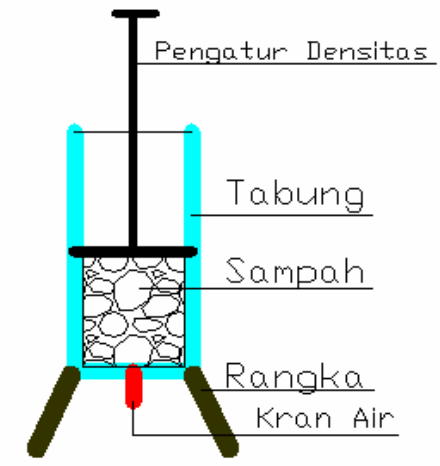

Gambar 6. Alat Ukur Field Capacity
Hasil penelitian lain menunjukan bahwa komposisi sampah domestik kota besar di Indonesia mempuyai kandungan organik berkisar $70 \%$. Tentunya sangat berbeda dengan sampah yang berasal dari negara yang teknologi dan tingkat hidup masyarakat yang tinggi. Sebagaimana diketahui bahwa benda yang bersifat organik, maka benda tersebut akan mudah berubah bentuk atau karakteristik fisiknya.

Adapun kadar sampah sangat dipengaruhi oleh kondisi iklim, ketika sampah diambil di samping umur sampahnya. Tentunya ketika pengambilan terukur akan berbeda dengan sampah yang diambil pada saat musim kemarau.

Penentuan nilai field capacity sampah dan material menggunakan 2 cara, yakni sampah tanpa dicacah (Alat ukur FC besar) dan sampah yang telah dicacah (Alat ukur FC kecil). Prosedur penentuan cara pertama, sampah yang diambil dari TPS yang sudah diketahui komposisi kepadatan dan kadar airnya, dimasukkan ke dalam alat ukur FC. Kepadatan sampah dalam alat ukur FC diatur

\section{HASIL DAN PEMBAHASAN} sampah pada musim hujan, kadar air sampah yang nilai FC pada kedua cara secara umum sama. Pada menggunakan alat pengatur kepadatan, kran ai ditutup, dan selanjutnya masukkan air sedemikian hingga sampah terendam air supaya sampah mengalami jenuh air.

Berdasarkan data yang telah dikumpulkan, hitung nilai $\mathrm{FC}$ sampah menggunakan rumus yang telah dijelaskan pada bab sebelumnya. Hasil penentuan nilai field capacity untuk sampah dan bahan lainnya dijelaskan pada Tabel 2.

Berdasarkan Tabel tersebut, tampak bahwa nilai Field capacity sampah sangat dipengaruhi oleh kepadatan dan umur sampahnya. Pada sampah yang kondisinya masih segar atau baru, maka nilai FC sampah relative lebih besar dibanding pada sampah yang sudah lama yakni sampah yang berasal dari TPA lama dan sampah composting.

76 |Media Teknik Sipil, Volume 9, Nomor 1, Februari 2011: 70
Tabel 2. Nilai Field Capacity

\begin{tabular}{llc}
\hline No & Jenis Sampah dan Material & Field Capacity $(\mathrm{mm} / \mathrm{m})$ \\
\hline 1 & Tempat Pembuangan Sementara Kebun Bibit & 349.14 \\
2 & Tempat Sampah Sabuga ITB & 329.37 \\
3 & Sampah Komposting & 320.77 \\
4 & Tempat Pembuangan Akhir Sampah Lama & 279.90 \\
5 & Pasir Cor & 241.86 \\
6 & Pasir merah & 375.11 \\
\hline
\end{tabular}

Sementara itu pada material pasir, tampak bahwa pasir merah memiliki nilai FC yang lebil besar dibanding nilai FC pada pasir cor (hitam). Hal tersebut, karena nilai FC sangat dipengaruhi oleh kepadatan material, dimana semakin tinggi kepadatan material maka nilai FC semakin rendah.

\section{KESIMPULAN}

Nilai field capacity (FC) dipengaruhi oleh umur sampah. Nilai FC sampah segar lebih besar dibanding nilai FC sampah lama. Disamping itu bahwa nilai FC dipengaruhi oleh kepadatan material. Nilai FC material dengan kepadatan lebih tinggi (pasir hitam), nilai FC lebih kecil.

\section{DAFTAR PUSTAKA}

Damanhuri, 2008, Landfilling limbah, Fakultas Teknik Sipil dan Lingkungan -Institut Teknologi Bandung.

Gregory, J., McCabe, Steven L. Maerkstrom, 2007, A monthly water-balance model driven by a Graphical user interface, U.S Department of the interior, U.S. Geological Survey. http://www.google.com. Download 4 Mei 2009

Hernández-Berriel, L. Marquez-Benavides, D.J. Gonzalez-Perez, O. Buenrostro-Delgado, 2008, The effect of moisture regimes on the araerobic degradation of municipal solid waste from Metepec (Mexico), Waste waste from Metepec (Me
management 28 : S14-S20.

Jang YS, Kim YW, Lee SI., 2002. Hydraulic properties and leachate level analysis of
Kimpo metropolitan Landfill, Korea. Waste Managemen 22:261-267.

Poulsen Tjalfe G, Moldrup Per, 2005, Factors affecting water balance and percolate production for a landfill in operation, Waste management \& Research 23, 72-78.

Schroeder, P. R. Dozier T. S., Zappi P. A., McEnroe B.M., Sjostrom J.W., Peyto R.L., 1994, The Hydrologic Evaluation of Landfill Performance (HELP) Model. User's Guide for Version 3; Engineering Documentation for Version 3, US Environmental Protection Agency, Cincinnati, Ohio.

Teresa Orta, Cruz, Rojas, Monje, Sanchez, 2003, Determination of field capacity of mucipal solid waste with surcharge simulation, Waste Management \& Research, Res 2003 : 21 : 137-144.

Tchobanoglous, G., Theisen, H., Vigil, S., 1993. Integrated Solid Waste Management Engineering Principles and Management Issues. McGraw-Hill Publishers, New York

Warith, M., Li, X., Jin, H., 2005, Bioreaktor Landfills; state of the art review, Emirats Journal for Engineering 10 (1).1-14.

2008, Undang-undang RI No 182008 tentang Pengelolaan sampah, Menteri Lingkungan hidup 